\title{
Ocular Surface Tolerability of Prostaglandin Analogs and Prostamides in Patients with Glaucoma or Ocular Hypertension
}

\author{
Andrew C. S. Crichton · Steven Vold · Julia M. Williams · David A. Hollander
}

To view enhanced content go to www.advancesintherapy.com Received: December 11, 2012 / Published online: March 7, 2013

(C) The Author(s) 2013. This article is published with open access at Springerlink.com

\section{ABSTRACT}

Introduction: There has been increased attention on the potential impact of the preservative benzalkonium chloride (BAK) on the ocular surface. This study compared the ocular surface tolerability of once-daily bimatoprost $0.01 \%$ and latanoprost $0.005 \%$ (both preserved with $0.02 \% \mathrm{BAK})$, and travoprost $0.004 \%$ preserved with sofZia ${ }^{\mathrm{TM}}$.

Methods: A randomized, multicenter (15 sites), investigator-masked study enrolled patients with

ClinicalTrials.gov \#NCT01253902.

A. C. S. Crichton $(\bowtie)$

University of Calgary, 102, 49 Richard Way SW, Calgary, $\mathrm{AB}$, Canada

e-mail: drcricht@telusplanet.net

S. Vold

Vold Vision, PLLC, Bentonville, AR, USA

J. M. Williams · D. A. Hollander

Allergan, Inc., P.O. Box 19534, Irvine, CA, 92623 USA

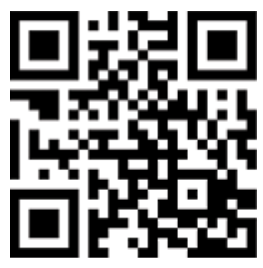

Enhanced content for Advances in Therapy articles is available on the journal web site: www.advancesintherapy.com open-angle glaucoma or ocular hypertension who had received latanoprost monotherapy for at least 1 month. Patients were randomized to oncedaily bimatoprost $(n=56)$, travoprost $(n=53)$, or latanoprost $(n=55)$ monotherapy for 3 months. Follow-up visits were at weeks 1,4 , and 12 . The primary outcome measure was physician-graded conjunctival hyperemia (scale 0 to 3 ) at week 12 . Secondary outcomes included corneal staining (scale 0 to 3 ) and tear break-up time (TBUT).

Results: There were no significant differences in mean (standard deviation [SD]) outcome measures including conjunctival hyperemia (bimatoprost: 0.48 [0.52], travoprost: 0.49 [0.52], latanoprost: 0.51 [0.54]), corneal staining (bimatoprost: 0.31 [0.49], travoprost: 0.25 [0.46], latanoprost: 0.24 [0.45]), or TBUT (bimatoprost: $9.7 \mathrm{~s}$ [6.1], travoprost: $9.5 \mathrm{~s}$ [5.8], latanoprost: $9.8 \mathrm{~s}$ [5.0]) among subjects at latanoprost-treated baseline $(P \geq 0.664)$. At week 12 , there were no significant differences in conjunctival hyperemia (bimatoprost: 0.42 [0.48], travoprost: 0.46 [0.44], latanoprost: 0.44 [0.57]), corneal staining (bimatoprost: 0.31 [0.45], travoprost: 0.32 [0.48], latanoprost: 0.22 [0.30]), or TBUT (bimatoprost: 9.7 s [5.7], travoprost $9.7 \mathrm{~s}$ [5.0], latanoprost: $9.3 \mathrm{~s}$ [4.0]) among the treatment groups $(P \geq 0.379)$. At week 1 , 
there was a statistically significant among-group difference in mean change from baseline in hyperemia $(+0.04$, bimatoprost; +0.20 , travoprost; 0.00 , latanoprost; $P=0.018$ ). There were no statistically significant among-group differences in mean corneal staining, mean TBUT, or change from baseline at any visit.

Conclusions: Despite preservative differences, there were no significant differences in objective clinical measures of ocular surface tolerability after 3 months of treatment with bimatoprost (with $0.02 \% \mathrm{BAK}$ ), travoprost (with sofZia), and latanoprost (with $0.02 \% \mathrm{BAK}$ ).

Keywords: Benzalkonium chloride; Bimatoprost; Conjunctival hyperemia; Glaucoma; Latanoprost; Ocular hypertension; Ophthalmology; sofZia; Travoprost

\section{INTRODUCTION}

The prostaglandin analogs and prostamides $[1,2]$ are commonly prescribed first-line medications for glaucoma or ocular hypertension based upon their efficacy in lowering intraocular pressure (IOP), favorable safety and tolerability profiles, and ease of once-daily dosing [3-5]. The most frequently reported side effect of these medications, conjunctival hyperemia, is often transient and not associated with inflammation or other negative sequelae $[4,6,7]$.

Prostaglandin analogs (travoprost and latanoprost) and prostamides (bimatoprost) are typically administered from multidose bottles that contain preservatives to ensure sterility. Benzalkonium chloride (BAK) is the most commonly used preservative in ophthalmic medications as a result of its broad-spectrum bactericidal and bacteriostatic activity at physiological pH [8-11]. The concentration of BAK in ophthalmic formulations varies over several fold, depending on the particular active agent; for example, bimatoprost $0.03 \%$ (Lumigan $^{\circledR}$; Allergan, Inc., Irvine, CA, USA) is preserved with $0.005 \%$ BAK and latanoprost $0.005 \%$ (Xalatan ${ }^{\circledR}$; Pfizer Inc, New York, NY, USA) with $0.02 \%$ BAK. Other preservatives have recently been employed; in particular, the proprietary system sofZia ${ }^{\mathrm{TM}}$ used in the formulation of travoprost $0.004 \%$ ophthalmic solution (Travatan $\mathrm{Z}^{\circledR}$; Alcon Laboratories, Inc., Fort Worth, TX, USA). In a recent clinical study, no statistically significant amonggroup differences were seen in patients after 3 months of use of once-daily bimatoprost $0.03 \%$ (preserved with $0.005 \% \mathrm{BAK}$ ), latanoprost (preserved with $0.02 \% \mathrm{BAK}$ ), and travoprost (preserved with sofZia) in objective measures of ocular surface tolerability, including conjunctival hyperemia, corneal staining, and tear break-up time (TBUT) [12].

While corneal toxicity secondary to BAK has been shown in prior in vitro and rabbit studies [13], it is unclear whether these studies accurately replicate ocular surface conditions in patients undergoing treatment with IOPlowering medications preserved with BAK. Exposure to BAK in some of these studies exceeds that experienced by many patients administering topical medications preserved with BAK.

Recently, a new formulation of bimatoprost $0.01 \%$ preserved with $0.02 \%$ BAK was approved. This formulation was designed to maintain the IOP-lowering efficacy of bimatoprost $0.03 \%$ and to provide an improved ocular surface tolerability profile. The present 12 -week study was undertaken to examine the ocular surface tolerability of once-daily bimatoprost $0.01 \%$ and latanoprost (both preserved with $0.02 \%$ BAK), and travoprost $0.004 \%$ (preserved with sofZia) in adult patients with glaucoma or ocular hypertension following a run-in on latanoprost. 


\section{MATERIALS AND METHODS}

\section{Study Design and Patient Disposition}

This was a 3-month, multicenter, randomized, investigator-masked, parallel-group comparison study conducted at 15 sites in the United States and Canada. The study was approved by the respective institutional review boards or independent ethics committees at each site and followed the regulations of the Health Insurance Portability and Accountability Act and the Good Clinical Practice guidelines of the Declaration of Helsinki. Written informed consent was obtained from all subjects or their legally authorized representatives.

Eligible patients were $\geq 18$ years of age, with best-corrected Snellen visual acuity of $\geq 20 / 100$ in both eyes, and diagnosis of ocular hypertension or chronic open-angle glaucoma, requiring antiglaucoma/ocular hypotensive agents. Key exclusion criteria were the use of bimatoprost or travoprost within the past 6 months, any corneal abnormalities (scar, edema, or keratoconus) preventing assessments of IOP, a history of refractive surgery or punctal plug use, a history of active ocular infection or inflammation, need for ocular medications other than the study treatments (intermittent use of BAK-free artificial tears was permitted), known sensitivity or allergy to study medications, any systemic disease that could confound study results, or in the opinion of the investigator, made the patient unsuitable for the study.

Newly diagnosed patients underwent a 30-day run-in on latanoprost $0.005 \%$ (Xalatan ${ }^{\circledR}$; Pfizer Inc, New York, NY, USA) monotherapy, while those who had been receiving latanoprost monotherapy continued treatment. Patients who were receiving combination or alternate medications at screening underwent a 30-day washout of all other medications, concomitant with administration of latanoprost monotherapy. At the baseline visit (day 0) patients discontinued latanoprost monotherapy and were randomized in a 1:1:1 ratio to three treatment groups: 1 ) bimatoprost $0.01 \%$ preserved with $0.02 \%$ BAK (Lumigan $^{\circledR} 0.01 \%$; Lumigan ${ }^{\circledR}$ RC; Allergan, Inc., Irvine, CA); 2) travoprost $0.004 \%$ preserved with sofZia (Travatan $Z^{\circledR}$; Alcon Laboratories, Inc., Fort Worth, TX); and 3) latanoprost $0.005 \%$ preserved with $0.02 \%$ BAK (Xalatan ${ }^{\circledR}$; Pfizer Inc, New York, NY). In this investigator-masked study, study medications (Lumigan ${ }^{\circledR} 0.01 \% /$ Lumigan $^{\circledR}$ RC, Travatan $Z^{\circledR}$, and Xalatan ${ }^{\circledR}$ ) were over-labeled and packaged into kits according to treatment groups A, B, and C, and made available for dispensing at the baseline visit (visit 2, day 0) and week 4 visit according to the randomization schedule. Masked study drugs were administered once daily as a single drop in each eye between 7:00 and 9:00 pm for 12 weeks.

\section{Assessments and Outcomes Variables}

Study visits were scheduled at consistent times in the morning, at baseline, and weeks 1, 4, and 12 . At each study visit, ocular tolerability and safety assessments were conducted. The primary outcome measure was bulbar conjunctival hyperemia at week 12. Observations were graded by a comparison with color photographic standards employing the following values: $0=$ none (normal); $0.5=$ trace (trace flush, reddish pink); 1 = mild (mild flush, reddish color); 2 = moderate (bright red color); and 3 = severe (deep, bright diffuse redness). Secondary outcome measures included corneal staining with fluorescein and TBUT using the slit lamp at $10 \times$ magnification. Corneal staining of superficial punctate keratopathy was graded on a scale of $0=$ none (no findings), $0.5=$ trace $(1-5$ puncta), $1=$ mild (6-20 puncta), $2=$ moderate ( $>20$ puncta), and $3=$ severe (too many puncta 
to count). Biomicroscopy was performed by the investigator (or designee) by slit lamp examination without pupil dilation.

Safety assessments included IOP measurements and adverse events. All IOP measurements were made once per visit before 12:00 pm as per protocol. Adverse events were recorded, with an assessment of severity (graded as mild, moderate, or severe), action taken, and relationship to study medication (graded as definite, probable, and not related).

\section{Statistical Analyses}

For purpose of analysis, the intent-to-treat (ITT) population included all subjects who were randomized to study medication. The per-protocol (PP) population, a subset of the ITT population, included all subjects who completed 12 weeks of treatment without significant protocol violations. The safety population included all subjects who were exposed to study medication.

Differences in outcomes among the treatment groups were analyzed using analysis of variance (ANOVA) for the among-group differences, using the ITT population, and last observation carried forward for missing values. In the analysis of conjunctival hyperemia, corneal staining, and TBUT, analyses were performed using the average value of both eyes. If the overall null hypothesis was rejected, pairwise comparisons were made using the two-sample $t$-test using the PP population. Change from baseline was summarized and analyzed similarly, including the use of a paired $t$-test for change within a treatment group. In addition, all biomicroscopy changes were summarized for change from baseline at week 12, and categorized as "no change," "decrease $\geq 0.5$," "increase $=0.5$," "increase $>0.5$," and "increase $\geq 1$." The analysis was performed using the ITT population and no hypothesis testing was performed.
Safety data were summarized for the safety population. For adverse events, among-group differences were analyzed using a two-tailed Fisher's exact test. IOP was averaged over both eyes for analysis, and the results at baseline and each follow-up visit were analyzed by ANOVA. Change from baseline in IOP was summarized at each follow-up visit using analysis of covariance with effects for treatment group and baseline IOP, while within-group change was analyzed using a paired $t$-test. All observed safety data were analyzed and there was no imputation for missing values.

A sample size of 49 subjects per treatment group provided: 1) $99 \%$ power to detect an among-group difference for all three treatment groups and 2) 95\% power to detect a 0.5 score difference in any pairwise comparison of conjunctival hyperemia. The significance level was set at 0.05 for each of these calculations based on the condition that pairwise comparisons are only to be performed if the overall among-group test is statistically significant.

\section{RESULTS}

\section{Patient Disposition}

In total, 164 patients (both ITT and safety population) were randomized to the three treatment groups (Table 1) and received study medication; the PP population comprised 150 patients. There were no significant differences among treatment groups in patient demographics or ocular diagnoses at baseline (Table 1). Treatment history of study population reveals that $68.9 \%$ had more than 1 year of treatment, $50.0 \%$ had at least 3 years, and $14.0 \%$ had more than 10 years of treatment with IOP-lowering medications. Eleven patients discontinued treatment before week 12 (Table 2). 
Table 1 Baseline characteristics of all enrolled patients

\begin{tabular}{|c|c|c|c|}
\hline Safety population & $\begin{array}{l}\text { Bimatoprost } 0.01 \% \\
(n=56)\end{array}$ & $\begin{array}{l}\text { Travoprost } 0.004 \% \text { with sofZia } \\
(n=53)\end{array}$ & $\begin{array}{l}\text { Latanoprost } 0.005 \% \\
(n=55)\end{array}$ \\
\hline Mean age (SD), years* & $65.1(11.76)$ & $63.2(13.57)$ & $64.7(12.28)$ \\
\hline Gender, male, $n(\%)^{* *}$ & $20(35.7)$ & $28(52.8)$ & $24(43.6)$ \\
\hline \multicolumn{4}{|l|}{ Race/ethnicity, $n(\%)^{* * *}$} \\
\hline Caucasian & $31(55.4)$ & $32(60.4)$ & $30(54.5)$ \\
\hline Black & $10(17.9)$ & $9(17.0)$ & $11(20.0)$ \\
\hline Hispanic & $10(17.9)$ & $8(15.1)$ & $10(18.2)$ \\
\hline Asian & $2(3.6)$ & $3(5.7)$ & $3(5.5)$ \\
\hline Other & $3(5.4)$ & $1(1.9)$ & $1(1.8)$ \\
\hline \multicolumn{4}{|l|}{ Diagnosis, $n(\%)^{* * * *}$} \\
\hline OAG & $37(66.1)$ & $35(66.0)$ & $33(60.0)$ \\
\hline $\mathrm{OHT}$ & $10(17.9)$ & $10(18.9)$ & $12(21.8)$ \\
\hline Other & $9(16.1)$ & $8(15.1)$ & $10(18.2)$ \\
\hline \multicolumn{4}{|l|}{ Treatment history, $n(\%)^{\mathrm{a}}$} \\
\hline$<1$ year & $5(8.9)$ & $9(17.0)$ & $10(18.2)$ \\
\hline $1-3$ years & $11(19.6)$ & $8(15.1)$ & $12(21.8)$ \\
\hline $3-5$ years & $10(17.9)$ & $10(18.9)$ & $9(16.4)$ \\
\hline $5-10$ years & $7(12.5)$ & $12(22.6)$ & $11(20.0)$ \\
\hline$>10$ years & $12(21.4)$ & $6(11.3)$ & $5(9.1)$ \\
\hline No medication at screening & $11(19.6)$ & $8(15.1)$ & $8(14.5)$ \\
\hline \multicolumn{4}{|l|}{ Medication at screening, $n(\%)$} \\
\hline PGA/PM only & $37(66.1)$ & $38(71.7)$ & $43(78.2)$ \\
\hline BB only & $2(3.6)$ & $3(5.7)$ & 0 \\
\hline PGA/PM+BB FC & $1(1.8)$ & $1(1.9)$ & $1(1.8)$ \\
\hline \multicolumn{4}{|l|}{ Other } \\
\hline $\mathrm{BB}+\mathrm{PGA} / \mathrm{PM}$ & $2(3.6)$ & $2(3.8)$ & $3(5.5)$ \\
\hline $\mathrm{BB}+\mathrm{CAI}$ & $1(1.8)$ & 0 & 0 \\
\hline $\mathrm{PGA} / \mathrm{PM}+\mathrm{CAI}$ & 0 & $1(1.9)$ & 0 \\
\hline PGA/PM+FC product & $2(3.6)$ & 0 & 0 \\
\hline
\end{tabular}

$B B$ beta blocker, $C A I$ carbonic anhydrase inhibitor, $F C$ fixed combination, $O A G$ open-angle glaucoma, $O H T$ ocular hypertension, $P G A$ prostaglandin analog, $P M$ prostamide, $S D$ standard deviation

${ }^{*} P=0.707$ based on two-sample $t$ test; ${ }^{* *} P=0.205 ;{ }^{* *} P=0.833$ both based on Fisher's exact test; ${ }^{* * *} P=0.993$

${ }^{a}$ Duration of one or more IOP-lowering medications before baseline 
Table 2 Reasons for discontinuation

\begin{tabular}{llll}
\hline$n(\%)$ & $\begin{array}{l}\text { Bimatoprost 0.01\% } \\
(n=56)\end{array}$ & $\begin{array}{l}\text { Travoprost 0.004\% with sofZia } \\
(n=53)\end{array}$ & $\begin{array}{l}\text { Latanoprost 0.005\% } \\
(n=55)\end{array}$ \\
\hline Patient decision & $1(1.8)$ & 0 & $2(3.6)$ \\
Investigator decision & $1(1.8)$ & 0 & 0 \\
Lost to follow-up & $1(1.8)$ & $1(1.9)$ & 0 \\
Adverse event & $1(1.8)$ & 0 & $2(3.6)$ \\
Other & $1(1.8)$ & $1(1.9)$ & 0 \\
\hline
\end{tabular}

Patient/investigator decision - patient/investigator decides it is best interest to be withdrawn

Adverse event - branch retina artery occlusion, left eye (bimatoprost); aspiration pneumonia resulting in death, punctured colon (latanoprost)

Other - protocol violation: use of prohibited medications

\section{Ocular Surface Tolerability}

\section{Hyperemia}

There were no significant differences in conjunctival hyperemia scores among groups at latanoprost-treated baseline. At 12 weeks (primary endpoint), the mean (standard deviation [SD]) conjunctival hyperemia score was $0.42(0.48)$ for bimatoprost, $0.46(0.44)$ for travoprost, and 0.44 (0.57) for latanoprost $(P=0.907)$. Statistically significant amonggroup differences were seen in change from baseline in conjunctival hyperemia at 1 week (0.04 [0.34] for bimatoprost, 0.20 [0.39] for travoprost, and 0.00 [0.42] for latanoprost; $P=0.018$; Fig. 1). Pairwise $t$-tests were significant for travoprost versus both bimatoprost $(P=0.034)$ and latanoprost $(P=0.007)$, but not for bimatoprost versus latanoprost $(P=0.542)$. Changes within groups were not significant at any visit for each of the bimatoprost and the latanoprost groups; however, with the travoprost group, change from baseline was significant at weeks 1 and 4, where the mean change (SD) in hyperemia was an increase of $0.20(0.39)$ at week $1(P<0.001)$ and an increase of $0.13(0.47)$ at week $4(P=0.046)$.

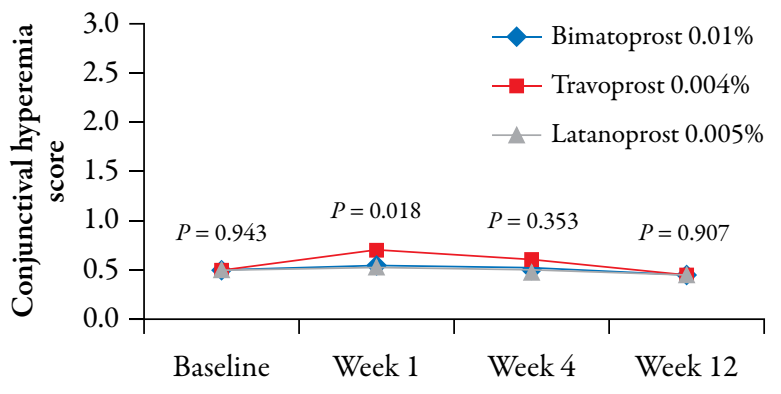

Fig. 1 Mean hyperemia score at each visit (intent-to-treat population)

\section{Corneal Staining}

There were no significant among-group differences in mean corneal staining at baseline or mean staining at any visit ( $P \geq 0.379$; Fig. 2$)$. At baseline, the mean (SD) corneal staining score was $0.31(0.49)$ in the bimatoprost group, 0.25 $(0.46)$ in the travoprost group, and $0.24(0.45)$ in the latanoprost group $(P=0.664)$. At 12 weeks, the mean (SD) score was $0.31(0.45)$ in the bimatoprost group, $0.32(0.48)$ in the travoprost group, and $0.22(0.30)$ in the latanoprost group $(P=0.379)$. Moreover, there were no significant among-group differences in the change from baseline corneal staining scores at weeks 1, 4, and $12(P \geq 0.237)$. At week 12 , the mean (SD) 


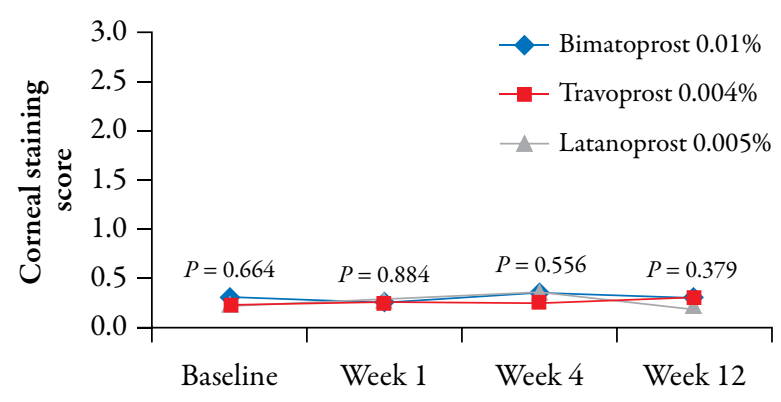

Fig. 2 Mean corneal staining scores at each visit (intent-totreat population)

change from baseline corneal staining scores was $0.00(0.44)$ in the bimatoprost group, 0.08 (0.50) in the travoprost group, and -0.02 (0.51) in the latanoprost group $(P=0.535)$. There were no significant changes from baseline within any of the treatment groups.

\section{Tear Break-up Time}

As with corneal staining, there were no statistically significant among-group differences in mean TBUT times at baseline or at any visit. Mean (SD) TBUT at baseline was 9.7 s (6.14) in the bimatoprost group, $9.5 \mathrm{~s}$ (5.77) in the travoprost group, and $9.8 \mathrm{~s}$ (5.00) in the latanoprost group $(P=0.951)$. At 12 weeks, the TBUT was $9.7 \mathrm{~s}(5.71)$ in the bimatoprost group, $9.7 \mathrm{~s}$ (4.96) in the travoprost group, and $9.3 \mathrm{~s}(4.04 ; P=0.871)$ in the latanoprost group. There were no significant differences among the treatment groups in mean TBUT at any follow-up visit $(P \geq 0.847$; Fig. 3$)$. Similarly, there were no significant amonggroup differences in the change from baseline at any visit $(P \geq 0.630)$. At week 12 , the mean (SD) changes from baseline TBUT were $0.0 \mathrm{~s}$ (4.47), $0.2 \mathrm{~s}$ (4.65), and $-0.5 \mathrm{~s}$ (2.92) in the bimatoprost, travoprost, and latanoprost groups, respectively. Moreover, there were no significant within-group changes from baseline for any of the three treatment groups.

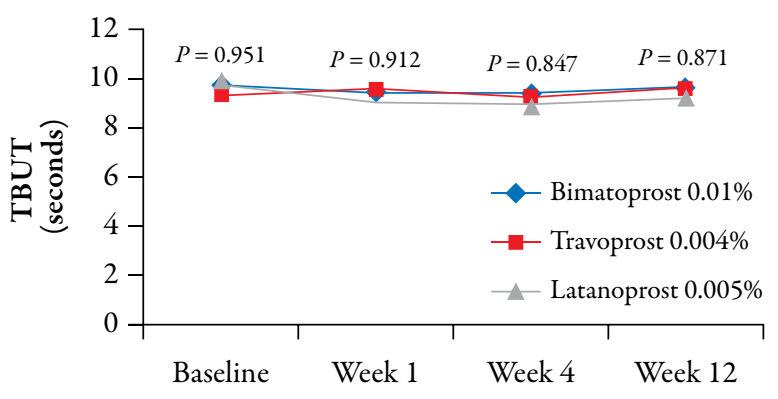

Fig. 3 Mean tear break-up time (TBUT) at each visit (intent-to-treat population)

\section{Biomicroscopy}

Overall, there was either no change or a decrease in conjunctival hyperemia from baseline in $88.2 \%$ of bimatoprost-treated patients, $70.6 \%$ of travoprost-treated patients, and $84.6 \%$ of latanoprost-treated patients at week 12 . A $\geq 1$-unit increase in conjunctival hyperemia from baseline at week 12 was observed in $2.0 \%$ of the bimatoprost group, $5.9 \%$ of the travoprost group, and 3.8\% of the latanoprost group (Fig. 4). There was either no change or a decrease in corneal staining in $76.5 \%$ of the bimatoprost group, $70.6 \%$ in the travoprost group, and $67.3 \%$ in the latanoprost group. $\mathrm{A} \geq 1$-unit increase in corneal staining was observed in $2.0 \%$ of the bimatoprost group, $5.9 \%$ of the travoprost group, and $3.8 \%$ of the latanoprost group (Fig. 4).

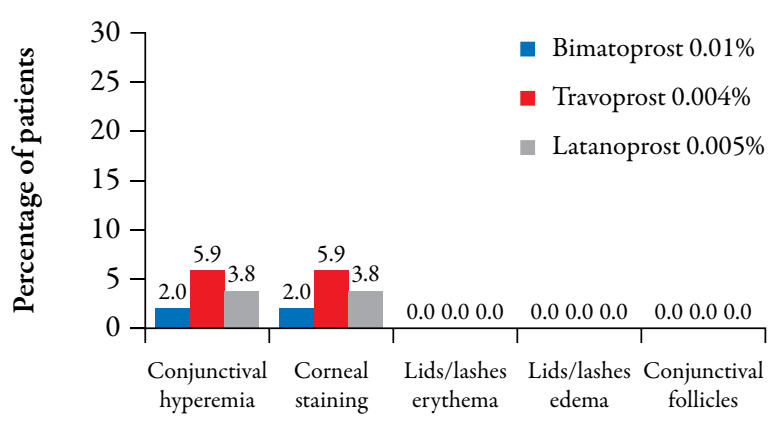

Fig. 4 Biomicroscopy findings. Incidence of $\geq 1$-unit increase in the severity of biomicroscopy findings from baseline to week 12 (intent-to-treat population) 


\section{Safety}

\section{Intraocular Pressure}

Intraocular pressure was not significantly different among the three groups at latanoprosttreated baseline $(P=0.232)$. There were no significant among-group differences in change from baseline at any follow-up visit $(P \geq 0.236$; Table 3). Bimatoprost demonstrated a statistically significant reduction in IOP from latanoprosttreated baseline at every follow-up visit (weeks 1 , 4 , and 12), ranging from mean (SD) reductions of 0.8 (2.67) $\mathrm{mmHg}$ at week 1 to 1.0 (3.01) $\mathrm{mmHg}$ at week 4, and $1.0(2.84) \mathrm{mmHg}$ at week 12 $(P \leq 0.039$; Table 3$)$. There were no statistically significant reductions from latanoprost-treated baseline in the travoprost group at either week 1 (0.7 [2.56] $\mathrm{mmHg}[P=0.056])$ or week 4 (0.5 [2.55] mmHg $[P=0.138])$. The change in IOP was significant only at week 12 for the travoprost group (1.0 [2.10] $\mathrm{mmHg}[P=0.001])$. There were no statistically significant changes in IOP from baseline following randomization in the latanoprost-treated group at any visit $(P \geq 0.239)$.

\section{Adverse Events}

All three treatments were well tolerated and adverse event incidence rates were comparable among groups (Table 4). The treatment-related ocular adverse events included two cases of itchy lids in the bimatoprost group, two cases of hyperemia and two cases of dryness in the travoprost group, and one case of ocular itching in the latanoprost group. No treatment-related serious adverse events were reported.

\section{DISCUSSION}

This study evaluated two prostaglandin analogs and a prostamide that differed in active agents and type of preservative. At 3 months, there were no significant differences among the study medications in objective clinical measures of ocular surface tolerability, including hyperemia, corneal staining, or TBUT, despite differences in type of preservative. Interestingly, among-group differences were seen in change from baseline to week 1 in conjunctival hyperemia $(P=0.018)$. While there were no statistically significant changes from the latanoprost-treated baseline in conjunctival hyperemia in the bimatoprost- or latanoprosttreated eyes at any visit, there was a statistically significant increase in hyperemia from latanoprosttreated baseline in the travoprost-treated eyes at both weeks $1(P<0.001)$ and $4(P=0.046)$.

Corneal staining and TBUT were not statistically significantly different among the groups at

Table 3 Within-group intraocular pressure changes from baseline in the safety population

\begin{tabular}{clll}
\hline & $\begin{array}{l}\text { Bimatoprost 0.01\% } \\
(n=56)\end{array}$ & $\begin{array}{l}\text { Travoprost 0.004\% with sofZia } \\
(n=53)\end{array}$ & $\begin{array}{l}\text { Latanoprost 0.005\% } \\
(n=55)\end{array}$ \\
\hline Baseline & 16.8 & 16.4 & 15.6 \\
Week 1 & -0.8 & -0.7 & -0.4 \\
$P$ value & 0.039 & 0.056 & 0.239 \\
Week 4 & -1.0 & -0.5 & -0.4 \\
$P$ value & 0.023 & 0.138 & 0.250 \\
Week 12 & -1.0 & -1.0 & -0.1 \\
$P$ value & 0.022 & 0.001 & 0.778 \\
\hline
\end{tabular}


Table 4 Adverse events

\begin{tabular}{llll}
\hline Safety population & $\begin{array}{l}\text { Bimatoprost 0.01\% } \\
(n=56)\end{array}$ & $\begin{array}{l}\text { Travoprost 0.004\% with sofZia } \\
(n=53)\end{array}$ & $\begin{array}{l}\text { Latanoprost 0.005\% } \\
(n=55)\end{array}$ \\
\hline No. of patients with $\mathrm{AE}^{*}$ & 6 & 5 & 5 \\
Ocular $^{* *}$ & 4 & 3 & 2 \\
Treatment-related ocular & 2 & 3 & 1 \\
No. of patients with SAE & 1 & 1 & 3 \\
\hline$A E$ adverse event, $S A E$ serious adverse event & \\
${ }^{*} P>0.999$ (Fisher's exact test); ${ }^{* *} P=0.771$ (Fisher's exact test) & \\
${ }^{a}$ All SAEs were unrelated to treatment &
\end{tabular}

latanoprost-treated baseline or at any follow-up visit. In addition, among-group differences in the change from baseline in these parameters were also not significant at any follow-up visit, nor were the changes from baseline within any of the three treatment groups.

This study was intended to assess the typical glaucoma patient population and did not exclude patients who may have had dry eye symptoms at baseline. The majority of patients (64\%) were diagnosed with glaucoma and most patients had been treated previously with IOP-lowering medications, with at least $50 \%$ of patients having received treatment for $\geq 3$ years (Table 1 ). Patients with punctal plugs were excluded to ensure that there were no differences in residence times of study medications on the ocular surface. The findings are in accord with an earlier report [12] using a similar protocol to compare bimatoprost, used at a higher concentration $(0.03 \%)$, travoprost, and latanoprost. The findings are also consistent with the analysis by Schwartz et al. of medical and pharmacy claims databases in which new patients initiated on latanoprost with BAK and travoprost with sofZia had similar rates of dry eye and ocular surface disease at 1 year [14].

While many preclinical studies using both in vitro and in vivo models have suggested that BAK may have a deleterious impact on the ocular surface, it is unclear whether these findings are clinically relevant. In at least some of these reports, BAK exposure is much greater than that experienced clinically [13]. Differences in ocular physiology between rabbits and humans, including the presence of a nictitating membrane [15] and differences in blink rate $[16,17]$, may account for some of the difference in findings between those preclinical studies and the present study. The present study demonstrates that over 3 months, there was no observable clinical impact on ocular surface tolerability parameters despite differences in preservatives and active agents.

In the present study, all patients were run in on latanoprost monotherapy for 30 days prior to baseline, which may impact tolerability results relative to patients naïve to IOP-lowering therapy. An additional limitation of this study was the duration of 3 months. Long-term studies that evaluate tolerability in patients receiving multiple topical medications and in patients with severe ocular surface disease are warranted.

\section{CONCLUSION}

Patients with glaucoma and ocular hypertension had comparable ocular tolerability findings with 
respect to objective measures of conjunctival hyperemia, corneal staining, and TBUT following 12 weeks of treatment. Differences in type of preservative (i.e., BAK vs. sofZia) did not lead to observable clinical differences in ocular surface tolerability at 3 months. Adverse event incidence rates were comparable among groups.

\section{ACKNOWLEDGMENTS}

This study was sponsored by Allergan, Inc. (Irvine, CA, USA). The authors acknowledge the editorial assistance of Jaspreet Grewal MSc, COMT, CCRP. Medical writing assistance was provided by Lauren Swenarchuk, PhD, and Diann Glickman, PharmD, of Evidence Scientific Solutions, Inc. and funded by Allergan, Inc. Dr. Crichton is the guarantor for this article and takes responsibility for the integrity of the work as a whole.

Conflict of interest. Dr. Crichton is a consultant for Allergan, Inc. and Alcon Laboratories, Inc. Dr. Crichton and Dr. Vold have conducted studies funded by Allergan, Inc. Julia Williams and Dr. Hollander are employees of Allergan, Inc. This study was supported by Allergan, Inc.

Open Access. This article is distributed under the terms of the Creative Commons Attribution Noncommercial License which permits any noncommercial use, distribution, and reproduction in any medium, provided the original author(s) and source are credited.

\section{REFERENCES}

1. Woodward DF, Krauss AH, Chen J, et al. The pharmacology of bimatoprost (Lumigan). Surv Ophthalmol. 2001;45:S337-45.

2. Woodward DF, Krauss AH, Chen J, et al. Pharmacological characterization of a novel antiglaucoma agent, Bimatoprost (AGN 192024). J Pharmacol Exp Ther. 2003;305:772-85.
3. McKee HD, Gupta MS, Ahad MA, Saldaña M, Innes JR. First-choice treatment preferences for primary open-angle glaucoma in the United Kingdom. Eye (Lond). 2005;19:923-24.

4. Holló G. The side effects of the prostaglandin analogues. Expert Opin Drug Saf. 2007;6:45-52.

5. Cracknell KP, Grierson I. Prostaglandin analogues in the anterior eye: their pressure lowering action and side effects. Exp Eye Res. 2009;88:786-91.

6. Abelson MB, Mroz M, Rosner SA, Dirks MS, Hirabayashi D. Multicenter, open-label evaluation of hyperemia associated with use of bimatoprost in adults with open-angle glaucoma or ocular hypertension. Adv Ther. 2003;20:1-13.

7. Leal BC, Medeiros FA, Medeiros FW, Santo RM, Susanna R, Jr. Conjunctival hyperemia associated with bimatoprost use: a histopathologic study. Am J Ophthalmol. 2004;138:310-13.

8. Novack GD, Evans R. Commercially available ocular hypotensive products: preservative concentration, stability, storage, and in-life utilization. J Glaucoma. 2001;10:483-86.

9. Furrer P, Mayer JM, Gurny R. Ocular tolerance of preservatives and alternatives. Eur J Pharm Biopharm. 2002;53:263-80.

10. Caraccio TR, McGuigan MA. Benzalkonium chloride. In: Dart RC, ed. Medical Toxicology, 3rd ed. New York, NY: Lippincott Williams \& Williams; 2004:1255-57.

11. Charnock C. Are multidose over-the-counter artificial tears adequately preserved? Cornea. 2006;25:432-37.

12. Whitson JT, Trattler WB, Matossian C, Williams J, Hollander DA. Ocular surface tolerability of prostaglandin analogs in patients with glaucoma or ocular hypertension. J Ocul Pharmacol Ther. 2010;26:287-92.

13. Baudouin C, Labbé A, Liang H, Pauly A, BrignoleBaudouin F. Preservatives in eyedrops: the good, the bad and the ugly. Prog Retin Eye Res. 2010;29:312-34.

14. Schwartz GF, Kotak S, Mardekian J, Fain JM. Incidence of new coding for dry eye and ocular infection in open-angle glaucoma and ocular hypertension patients treated with prostaglandin analogs: retrospective analysis of three medical/pharmacy claims databases. BMC Ophthalmol. 2011;11:14. 
15. Champeau EJ, Edelhauser HF. Effect of ophthalmic preservatives on the ocular surface: conjunctival and corneal uptake and distribution of benzalkonium chloride and chlorhexidine digluconate. In: Holly FJ, ed. The Preocular Tear Film in Health, Disease and Contact Lens Wear. Lubbock, TX: Dry Eye Institute; 1986:292-302.
16. Mishima S, Maurice DM. The oily layer of the tear film and evaporation from the corneal surface. Exp Eye Res. 1961;1:39-45.

17. Himebaugh NL, Begley CG, Bradley A, Wilkinson JA. Blinking and tear break-up during four visual tasks. Optom Vis Sci. 2009;86:E106-14. 